International Conference on Computational and Experimental Engineering \& Sciences 2008 (ICCES'08): Symposium “Image ProCESSING AND ANALYSIS"

17-22 Março 2008 em Honolulu, Estados Unidos da América

No âmbito da International Conference on Computational and Experimental Engineering \& Sciences 2008 (ICCES'08), irá ser realizado um Simpósio sobre processamento e análise de imagem organizado por investigadores portugueses da Universidade do Porto. Dos tópicos a serem abordados no evento incluem-se a recuperação, descrição, compressão e segmentação de imagem, a descrição, pesquisa, comparação, reconstrução e registo de objectos, o desenvolvimento de software para o processamento e análise de imagem e aplicações de processamento e análise de imagem. Para informações mais detalhadas, aceder à página web da ICCES'08.

E-mail: tavares@fe.up.pt

URL : icces.org/cgi-bin/ices08/pages/index

II Encontro Nacional de Bromatologia, Hidrologia e Toxicologia 17-18 ABRIL 2008 EM LISBOA

O II Encontro Nacional de Bromatologia, Hidrologia e Toxicologia, organizado pela Ordem dos Farmacêuticos, realiza-se nos dias 17 e 18 de Abril de 2008 na Faculdade de Farmácia da Universidade de Lisboa. O programa do evento consiste em comunicações orais e em poster abordando os seguintes tópicos: análise de contaminantes e resíduos, suplementos botânicos e dietéticos, detecção e análise de toxinas naturais, questões emergentes em segurança alimentar, fertilizantes e tópicos relacionados, nutrição, métodos analíticos, microbiológicos e toxicológicos e qualidade. Os detalhes relativos à inscrição no encontro podem ser obtidos na respectiva página web.

E-mail: colegios@ordemfarmaceuticos.pt

URL: www.ordemfarmaceuticos.pt

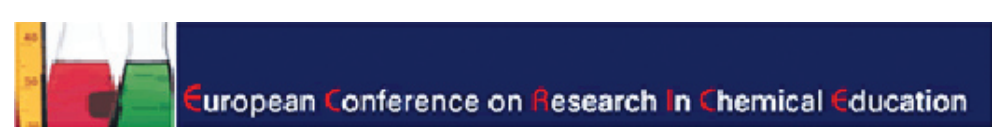

$9^{\text {Th }}$ ECrice (European Conference on Research in Chemical Education)

6-9 Julho 2008 em Istambul, TuRquia

A 9th European Conference on Research in Chemical Education ( $9^{\text {th }}$ ECRICE) irá decorrer em 2008 em Istambul. As conferências ECRICE realizam-se bienalmente desde há duas décadas e são o ponto alto dos eventos organizados pela Divisão de Ensino da Química da EuCheMS (Associação Europeia para as Ciências Química e Moleculares, da qual a SPQ é sócia fundadora). A série de conferências ECRICE pretende promover a investigação no ensino da química em todos os níveis onde a química é ensinada, desde a primária até ao ensino superior. A ênfase está na investigação e não na prática, embora as duas estejam frequentemente relacionadas. As conferências ECRICES reunem professores universitários, educadores e professores de química de toda a Europa, fornecendo um fórum Pan-Europeu único para a partilha dos resultados de investigação obtidos sobre o ensino e a aprendizagem da química. A próxima edição da ECRICE será na Turquia em 2008, um país com uma comunidade muito activa na investigação sobre o ensino da química. A localização da conferência, na fronteira entre a Europa e o Médio Oriente, irá também permitir uma maior participação de países da Europa de Leste e do Médio Oriente. Os tópicos da conferência incluem: (i) programas e projectos educacionais na Europa, (ii) a nanoquímica e o ensino da química, (iii) estudos de química no contexto do processo de Bolonha, (iv) química verde e ensino de química ambiental, (v) investigação em ensino da química, (vi) história da química, (vii) química e indústria, (viii) educação contínua, (ix) aprendizagem e ensino da química, (x) o passado e o futuro dos manuais de química e (xi) o ensino da química e ética.

E-mail: tkd@turchemsoc.org

URL: www.ecrice2008.org 
$4^{\text {Th }}$ International Conference on Diffusion in Solids (DSL-2008)

9-11 Julho 2008 em Barcelona, Espanha

A 4a Conferência Internacional sobre Difusão em Sólidos (DSL-2008) irá realizar-se em Barcelona entre 9 e 11 de Julho de 2008. A organização da DSL-2008 tem como objectivo reunir os investigadores das instituições de ensino superior e de investigação e de laboratórios envolvidos no estudo da difusão em sólidos, proporcionando assim uma plataforma adequada para a troca de ideias, para a criação de redes, para a divulgação de informação relevante e para a reflexão sobre os desafios futuros a enfrentar pelos investigadores interessados no tema. Na DSL-2008 estão previstas três sessões especiais: (i) termodinâmica, cinética e estrutura de interfaces e fenómenos associados, (ii) transferência de massa e de calor em meios porosos e (iii) transferência de calor em materiais celulares e compósitos - escoamento de gases e de líquidos, convecção e radiação. A data limite para submissão de trabalhos é 25 de Março de 2008. Para mais informações visitar a página web do evento.

E-mail: info@ironix-conferences.com

URL: www.dsl2008-barcelona.com

iUPaC Conference on Physical Organic Chemistry (IPCOC2008)

13-18 Julho 2008 em Santiago de Compostela, Espanha

A edição de 2008 da IUPAC Conference on Physical Organic Chemistry (IPCOC2008) irá decorrer na Universidade Real de Santiago de Compostela, Espanha, entre 13 e 18 de Julho de 2008. As conferências IPCOC são especialmente dedicadas aos cientistas com actividade na área da Química-Física Orgânica e Reactividade, abrangendo a diversidade da investigação na fronteira do conhecimento, sendo dado ênfase às suas interacções com outras áreas. O programa do evento inclui lições plenárias e convidadas e sessões orais e em poster. O programa científico, bem como informações relativas à inscrição e submissão de trabalhos podem ser obtidas na página web do evento.

E-mail: secretary@icpoc2008.org

URL: www.icpoc2008.org

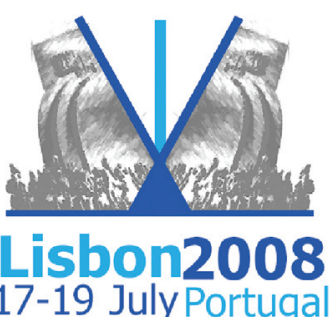

$6^{\text {TH }}$ InTERnational Vanadium Symposium (V6-2008) 17-19 JULHO 2008 EM LISBOA

O 6o Simpósio Internacional do Vanádio vai realizar-se em Lisboa de 17 a 19 de Julho de 2008 na Fundação Calouste Gulbenkian. É organizado através do Centro de Química Estrutural do Instituto Superior Técnico - UT Lisboa. A Sociedade Portuguesa de Química associa-se a este simpósio como entidade patrocinadora. As edições anteriores deste simpósio bienal reuniram tipicamente participantes de mais de 20 países. As áreas temáticas em foco são a Química e Bioquímica do Vanádio. Este campo de investigação é bastante vasto e engloba áreas de investigação fundamental e aplicada, nomeadamente: Química Inorgânica, de Coordenação e Biológica do Vanádio; Vanádio em Catálise (compostos orgânicos, polímeros, utilização industrial); Aplicações Terapêuticas de Compostos de Vanádio; Enzimologia, Toxicologia e Transporte; Polivanadatos, Novos Materiais e Processos.

Prevê-se que todos os grupos internacionais com trabalhos relevantes sobre a Química e Bioquímica do Vanádio estarão presentes. $06^{\text {th }}$ International Vanadium Symposium pretende ser uma excelente oportunidade para a apresentação e discussão de novos resultados e desenvolvimentos nos diversos tópicos de investigação e para o encontro de todos os interessados nestes temas que envolvem o vanádio.

A data limite para submissão de resumos é 15 de Maio de 2008, podendo os trabalhos ser apresentados em sessões orais ou em poster. O programa disponível à data e outras informações relevantes podem ser obtidas na página web da V6-2008.

E-mail:v6@spq.pt

URL: www.vanadiumsix.com 


\section{EONII:010 2008}

CONTROlO'2008 - 8th Portuguese Conference on Automatic Control

21-23 Julho 2008 em Vila Real, Portugal

A 8a Conferência Portuguesa de Controlo Automático (CONTROLO'2008) irá decorrer em Vila Real entre 21 e 23 de Julho de 2008. A CONTROLO'2008 apresenta-se como uma oportunidade excelente para apresentar novos resultados e discutir os desenvolvimentos mais recentes da investigação na área do controlo automático. A conferência encontra-se organizada em três tipos de sessões: lições plenárias, dadas por especialistas na área, sessões orais e sessões em poster. O programa de trabalhos incidirá nos desenvolvimentos teóricos e implementações práticas em todas as áreas do conhecimento envolvendo sistemas e controlo. Informações detalhadas sobre o evento podem ser obtidas na respectiva página web.

E-mail: controlo2008@utad.pt

URL: home.utad.pt/controlo2008

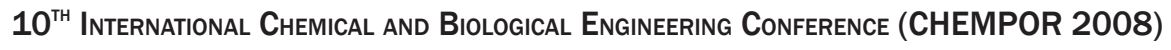
4-6 Setembro 2008 em Braga

A 10ạ edição da Conferência Internacional de Engenharia Química e Biológica (CHEMPOR) irá decorrer em Braga de 4 a 6 de Setembro de 2008, sendo organizada pelo Departa-

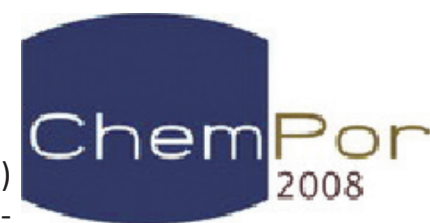
mento de Engenharia Biológica da Universidade do Minho e pela Ordem dos Engenheiros. A Sociedade Portuguesa de Química associa-se a este evento como entidade patrocinadora.

Tradicionalmente, a CHEMPOR reúne académicos, cientistas, engenheiros, empresários e clientes para discutir os desenvolvimentos mais recentes nas diferentes áreas da engenharia química e biológica. Um dos tópicos principais da CHEMPOR 2008 é a Qualidade de Vida, devido à importância da engenharia química e biológica nesta área. Este tópico é complementado por outros que incluem as Ciências e os Fundamentos da Engenharia, Processos Industriais e Engenharia de Processos. Está também previsto um painel de discussão sobre Educação em Engenharia Química e Biológica.

A CHEMPOR 2008 pretende assim fornecer uma excelente oportunidade para a apresentação de novos resultados e para a discussão dos tópicos de investigação mais recentes e dos novos desenvolvimentos na área da engenharia química e biológica.

A data limite para a submissão de resumos alargados é 18 de Março de 2008. Estes serão analisados pela Comissão Científica e publicados no livro de resumos. Será dado ênfase especial a contribuições da indústria e a desenvolvimentos resultantes de colaborações entre a indústria e o meio académico. Todos os autores que irão apresentar comunicações deverão fazer o seu registo na Conferência até 15 de Julho de 2008.

E-mail: chempor2005@eq.uc.pt

URL: www.deb.uminho.pt/chempor2008

$2^{\circ}$ Congresso Europeu de Química

16-20 Setembro 2008 em Torino, Itália

O 2ํ Congresso Europeu de Química será co-organizado pela EuCheMS e pela Sociedade Italiana de Química. É um evento muito importante para todas as Sociedades de Química Europeias, sendo esperada uma grande participação dos seus membros, oriundos de Universidades, Indústria e de Instituições Públicas e Privadas de Investigação e Análise.

Como determinado pela EuCheMS, os principais objectivos destes congressos, que reúnem todos os ramos das ciências química e molecular são: a promoção da química e da ciência química e molecular na fronteira do conhecimento, a dinamização da colaboração entre cientistas a trabalhar em investigação, na indústria e na educação, para desenvolver a química Europeia e a melhoria da imagem da química na sociedade.

O Congresso será organizado em sessões comuns, através de lições plenárias proferidas por cientistas de renome, e em sessões paralelas, focando áreas importantes da química. O programa destas sessões paralelas incluirá lições temáticas e lições convidadas, assim como comunicações orais e em poster, seleccionadas dos resumos submetidos.

E-mail: info@euchems-torino2008.it

URL: www.euchems-torino2008.it

Secção compilada por Helder Gomes 